\title{
Analyzing the Role of Business Resilience as SME's Core Competence to Improve Business Performance on Pandemic Crisis: A Study on Indonesian' SMEs
}

\author{
Lilik Purwanti ${ }^{1, *}$ Raditha Hapsari ${ }^{2}$
}

\author{
${ }^{1,2}$ Brawijaya University, Indonesia \\ *Corresponding author. Email: lilik@ub.ac.id
}

\begin{abstract}
The objective of this study is to examine the relationship between business resilience on business performance. The pandemic caused by Corona Virus Disease (Covid-19) has become an unpredictable threat for business owners and managers to sustain their business performance. Resilience has been identified as a strong determinant of a business's performance sustainability when facing a crisis such as natural disasters or pandemic outbreaks. However, the observation of resilience from recent studies has been conducted on a unidimensional variable. This study proposed that the observation of resilience should be done in multiple dimensions, to gain more insight into how the relationship between resilience and business performance operates. We proposed a conceptual framework to achieve the objective. In addition, we add two variables that are suggested to be determinants of business performance by previous studies. 286 Indonesian Small Medium Enterprises (SME) owners and managers participate as a respondent in this study. A Partial Least Square (PLS) analysis was conducted to analyze the data collected from a self-administered questionnaire. This study found that resilience could be examined into twodimensional observation because there is a different influence on business performance from adaptive resilience and planned resilience. Theoretical and practical implications are presented within the study.
\end{abstract}

Keywords: Business Resilience, Business Performance, SME, Pandemic Crisis.

\section{RESEARCH BACKGROUND}

Entrepreneurs have been recognized as an important factor that contributes to the economic development of a nation. [1] suggested that small firms serve as economic agents of change from their entrepreneurial activity. In addition, small firms have an important role in stimulating industry evolution and generating new job opportunities. According to data published by The Ministry of Creative Industry of Indonesia in 2018, Indonesia's culinary and traveling industry is one of the sectors with the highest contribution of the nation's Gross Domestic Product (GDP). However, these two sectors are facing a threatening challenge recently following the pandemic outbreak caused by the Corona Virus Disease 19 (Covid-19).

The social distancing regulation and several lockdowns directly impact the industry that relies heavily on interaction between service providers and their customers. [26] mentioned that following the social distancing regulations, public spaces have been either shut down or given strict operational procedures by the government. These restrictions challenge the business owner to review their strategic decisions and decide any reconciliation that should be made to survive the crisis. Researchers have found that business resilience is an important determinant of business performance [8], [15] . The resilience of a business could be measured by three dimensions: hardiness, optimism, and resourcefulness [29].

In addition to its impact on business performance, researchers also found that business resilience play an important role in improving entrepreneurial creative self-efficacy [8], [9], [16] and entrepreneurial innovation [5], [24]. Following these findings, we follow the suggestion from [8] to examine the relationship between business resilience, entrepreneurial creative self-efficacy, innovation, and business performance. To present our current a novelty to our current study, we try to examine the impact of business resilience as a multidimensional observation in contrast to previous researches that 
have been examined the variable as a unidimensional observation.

The purpose of distinguishing the business resilience as a multidimensional observation and a unidimensional observation is following the research results [23] that found organizational resilience as a significant predictor of financial performance. They proposed that organizational resilience could be observed by two-dimensional observation: adaptive resilience and planned resilience. The adaptive resilience of an organization is emerging after the organization faces a threat or challenge that requires leadership, social capital, internal collaboration, experience, and support from staff to survive the threat or challenge. Meanwhile, planned resilience is the organization's preparation to overcome predicted threats or challenges within the business environment. The pandemic outbreak is considered an unpredicted threat for the business owner, which will test their business resilience to sustain or improve their business performance. Thus, distinguishing the observation of business resilience into adaptive resilience and planned resilience could give a deeper insight into which type of resilience is needed by entrepreneurs to create a sustainable business performance in the pandemic crisis.

Following the proposed phenomenon and research objective, we proposed a conceptual framework to examine the relationship between adaptive resilience, planned resilience, creative self-efficacy, innovation, and business performance. The Indonesian' Small Medium Entreprises (SME) owner was selected as our research respondent. Theoretical and practical contribution is presented following the results found in this research.

\section{LITERATURE REVIEW}

\subsection{Business Resilience and Business Performance}

Resilience is a concept that has been studied in multiple fields of knowledge. In the management studies, resilience has been examined as organizational resilience, community resilience, and entrepreneurial resilience [20], [22], [23]. Management studies researchers defined resilience as the capacity of an organization to absorb shocks and downturns in the market environment by adapting their business models, strategies, and organizational structures [19]. Several measurements have been introduced to measure the resilience of a business or organization. [6] measure resilience with three dimensions: flexibility, motivation, and perseverance. Recently, [3] provided a new construct measurement for business resilience as a set of qualities that includes hardiness, resourcefulness, and optimism.

[23] proposed that business or organization resilience could be observed as multidimensional observation and a unidimensional observation usually conducted in recent research. The proposed dimensions to observe organizational resilience are adaptive resilience and planned resilience. An adaptive resilience is the competence of an organization to overcome threats and challenges within the business environment. Adaptive resilience is determined by the organization's leader, social capital, internal collaboration, organizational experience, and support from their employee. Planned resilience is a planned preparation to overcome predicted threats or challenges from the business environment. [23] research results showed that resilience has a significant impact on financial performance.

Business performance is an evaluation of an organization or firm achievement accordingly to its business objectives. Business performance could be measured following a firm's financial performance and market growth. [13] measures a firm's performance according to its production size, market share, and the quality of its product. The sustainability of a business performance could be affected a firm's external environment, such as economic crisis [2], [29]. Factors such as pandemic outbreaks or natural disasters have been acknowledged to cause an economic crisis following their impact on social activities.

Following the reviewed research results, the first two hypotheses we proposed in this study are:

H1: Adaptive resilience has a positive and significant impact on business performance

$\mathrm{H} 2$ : Planned resilience has a positive and significant impact on business performance

\subsection{Creative Self-efficacy}

Self-efficacy is the measurement of personal competencies. The concept of self-efficacy was popularized by [4], which was defined as the individual's belief in performing any given tasks or responsibilities. Creative self-efficacy is the derived form of self-efficacy which measures the individual beliefs of their ability to generate a creative idea or innovation [28]. Creative self-efficacy is considered 
as a cognitive resource on an individual or organizational level [24]. On the organizational level, it measures the competencies of the organization member to generate creative ideas or innovation to improve the organization's performance. [11] suggested that creative self-efficacy within the organization could influence their dynamic capability. Dynamic capability is defined as the capacity or competence of an organization to utilize and modify its resources accordingly to the changes within the business environment.

[8] have proved that resilience could improve entrepreneurial creative self-efficacy. In addition, the research also found that creative self-efficacy could improve business performance. The findings support the suggestion from [28] that creative self-efficacy could improve a firm's creative productivity, leading to better business performance. Creativity generated from a creative individual is also found to improve the individual performance of frontline employees such as restaurant staff or tour guides [30]. Following the reviewed research results the third to fifth hypotheses proposed in this study are:

H3: Adaptive resilience has a positive and significant impact on creative self-efficacy

H4: Planned resilience has a positive and significant impact on creative self-efficacy

H5: Creative self-efficacy has a positive and significant impact on business performance

\subsection{Innovation}

Entrepreneurs and innovation have been linked since the introduction of The Entrepreneurship Theory of Innovation by [25]. The innovation generated by entrepreneurs is considered to disturb or destroy the current economic structures and replace them with a new and innovative practical approach in pursuit of competitive advantage. Entrepreneurs are challenged to achieve an economical advantage by implementing new and innovative methods on their business operations [10]. The implementation of new and innovative business operations such as creating a new product or service offering or innovating the current business model could build a strong competitive advantage that could limit the competitors to imitate the business operations, thus improving the business performance in long term [12], [17].

On small and medium-sized enterprises (SME), the implementation of innovation exposed the enterprises to several risks [8]. Financial capital and limited resources have been identified as the strongest barriers for SMEs to implement innovation that has been generated [18]. In addition, innovation generated by SMEs is also considered easy to imitate by their competitors thus providing other threats for them to create competitive advantages for a sustainable and developing their business [21]. To overcome these challenges, entrepreneurs should continuously create innovation that is always ahead of their competitors to minimize the challenge by their competitors toward their competitive advantages [17].

[8] have confirmed that resilience has a positive and significant impact on entrepreneurial innovation. This result supports previous research suggesting the relationship between entrepreneurial resilience and innovation [3], [5]. [24] explained that resilience could nurture creativity and innovation by reducing stress or negative emotional response, improving individual creative thinking skills. Following the reviewed research results, the sixth to eighth hypotheses proposed in this study are:

H6: Adaptive resilience has a positive and significant impact on innovation

H7: Planned resilience has a positive and significant impact on innovation

H8: Innovation has a positive and significant impact on business performance

\section{METHODS}

This study is explanatory research, which aims to explain the relationship between business resilience, creative self-efficacy, innovation, and business performance. Business resilience has been found to significantly impact business performance [8]. However, the observation of business resilience effect on business performance has been observed undimensionally. Following recent results from [23] we predicted that resilience could be observed with two-dimensional observation. The first proposed resilience observation is adaptive resilience and the second is planned resilience. In addition to examining the direct effect of both business resilience dimensions on business performance, we also proposed that adaptive resilience and planned resilience have a significant effect on creative selfefficacy and innovation following research results [8]. Thus, to examine the proposed hypotheses for each relationship between variables, we build a conceptual framework which is shown in Figure 1. 


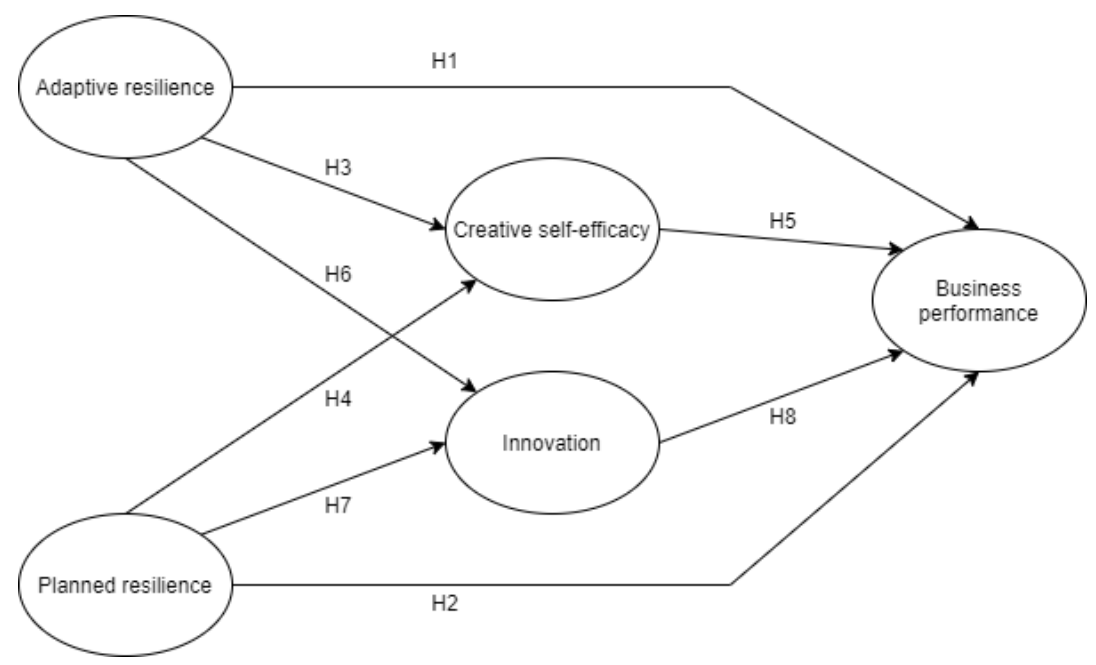

Figure 1 Proposed Conceptual Framework

To measure the robustness of the proposed conceptual framework to examine the relationship between the variables, Partial Least Square (PLS) analysis was conducted by utilizing the software SmartPLS 3.2. The analysis consists of two evaluations. First is the outer model analysis to examine the validity and reliability of the measurement for variables within the proposed model. The second one is the inner model analysis which is conducted to measure the fitness of the proposed model to examine the relationship between the variables [7]. The hypotheses testing could be conducted if the proposed model passes the outer model and inner model evaluation.

The unit of analysis for this study is the owner or manager of Indonesian Small Medium-Entreprises
(SME) in the culinary industry. A total of 300 selfadministered questionnaires were sent directly or by email to the respondent, selected by purposive sampling method. The criteria for a respondent to be eligible to fill out the questionnaire were: (1) their business has been run for more than 3 years; (2) is not a franchise or international network business.

\section{RESULTS AND DISCUSSION}

A total of 286 questionnaires were returned and have a complete dataset for the Partial Least Square (PLS) analysis. This yield more than a 95\% response rate, which could conclude that the research instrument used in this study is good. The characteristics of respondents shown by the following table:

Table 1. Respondents' Characteristics

\begin{tabular}{|l|l|c|c|}
\hline \multicolumn{2}{|l|}{ Variable } & Frequency (s) & Percentage (\%) \\
\hline \multirow{3}{*}{ Gender } & Male & 198 & $69 \%$ \\
\cline { 2 - 4 } & Female & 88 & $31 \%$ \\
\hline \multirow{5}{*}{ Age } & $18-25$ years old & 30 & $10 \%$ \\
\cline { 2 - 4 } & $26-35$ years old & 49 & $17 \%$ \\
\cline { 2 - 4 } & $36-45$ years old & 58 & $20 \%$ \\
\cline { 2 - 4 } & $46-55$ years old & 105 & $37 \%$ \\
\cline { 2 - 4 } & $>55$ years old & 44 & $15 \%$ \\
\hline \multirow{5}{*}{ Background } & High school & 66 & $23 \%$ \\
\cline { 2 - 4 } & Diploma & 89 & $31 \%$ \\
\cline { 2 - 4 } & Bachelor Degree & 87 & $30 \%$ \\
\cline { 2 - 4 } & Master Degree & 43 & $15 \%$ \\
\cline { 2 - 4 } & Doctoral Degree & 0 & $37 \%$ \\
\hline \multirow{5}{*}{ Business Period } & $3-5$ years & 107 & $34 \%$ \\
\cline { 2 - 4 } & 6-10 years & 98 & $15 \%$ \\
\cline { 2 - 4 } & $11-15$ years & 42 & $3 \%$ \\
\cline { 2 - 4 } & $>15$ years & 29 & 9 \\
\cline { 2 - 4 } & not stated & 9 & \\
\hline
\end{tabular}

\footnotetext{
Source: Own compilation based on field study
} 


\subsection{Outer Model Analysis}

The outer model analysis consists of three measurements, convergent validity, discriminant validity, and composite reliability. Convergent validity was measured to examine if the proposed variable measurement proposed in the conceptual model was fit to observe their respective variables. To pass the convergent validity measurement, each item for measurement should have an outer loading score of more than 0.5 considering that the composite reliability score for the observed variable is more than 0.7 [14]. One of the items to measure the planned resilience have an outer loading factor score below 0.5 , thus should be eliminated from the proposed model because it could not observe its respective variable. The results of convergent validity measurement are shown in Table 2.

Table 2. Convergent Validity Measurement

\begin{tabular}{|c|c|c|c|}
\hline Variable & Measurement & Loading Factor & Mark \\
\hline \multirow{3}{*}{$\begin{array}{l}\text { Creative self- } \\
\text { efficacy }\end{array}$} & CSE1 & 0,763 & Valid \\
\hline & CSE2 & 0,550 & Valid \\
\hline & CSE3 & 0,830 & Valid \\
\hline \multirow{5}{*}{ Innovation } & INO1 & 0,844 & Valid \\
\hline & INO2 & 0,738 & Valid \\
\hline & INO3 & 0,837 & Valid \\
\hline & INO4 & 0,746 & Valid \\
\hline & INO5 & 0,797 & Valid \\
\hline \multirow{5}{*}{$\begin{array}{l}\text { Business } \\
\text { performance }\end{array}$} & BP1 & 0,676 & Valid \\
\hline & $\mathrm{BP} 2$ & 0,769 & Valid \\
\hline & BP3 & 0,851 & Valid \\
\hline & BP4 & 0,848 & Valid \\
\hline & BP5 & 0,804 & Valid \\
\hline \multirow{5}{*}{$\begin{array}{l}\text { Adaptive } \\
\text { resilience }\end{array}$} & AR1 & 0,871 & Valid \\
\hline & AR2 & 0,899 & Valid \\
\hline & AR3 & 0,724 & Valid \\
\hline & AR4 & 0,835 & Valid \\
\hline & AR5 & 0,779 & Valid \\
\hline \multirow{5}{*}{$\begin{array}{l}\text { Planned } \\
\text { resilience }\end{array}$} & PR1 & 0,879 & Valid \\
\hline & PR2 & 0,855 & Valid \\
\hline & PR3 & 0,793 & Valid \\
\hline & PR4 & 0,769 & Valid \\
\hline & PR5 & 0,490 & Not Valid \\
\hline
\end{tabular}

The second measurement on outer model analysis is the discriminant validity measurement. This measurement examines if the proposed variable measurement within the conceptual model is best fitted for their respective observed variable, not for another variable. To examine if there is a discriminant validity problem, the Fornell-Larcker Criterion results could be used [14]. If the Average Variance Extracted (AVE) of an observed variable is more than other variables within the model, we could conclude that there is no discriminant validity problem. The AVE value of the Fornell-Larcker Criterion results is shown in Table 3.

Table 3. Fornell-Larcker Criterion Results

\begin{tabular}{|c|c|c|c|c|c|}
\hline \multirow{2}{*}{ Variable } & \multicolumn{5}{|c|}{ Fornell-Larcker } \\
\cline { 2 - 6 } & CSE & INO & BP & AR & PR \\
\hline CSE & 0,724 & & & & \\
\hline INO & 0,485 & 0,794 & & & \\
\hline BP & 0,546 & 0,524 & 0,792 & & \\
\hline AR & 0,420 & 0,611 & 0,617 & 0,824 & 0,770 \\
\hline PR & 0,460 & 0,571 & 0,447 & 0,616 & \\
\hline
\end{tabular}


Following the AVE results for each variable shown in Table 2, we could conclude that there is no discriminant validity problem for the measurement in the proposed model. Finally, the third measurement for outer model analysis is the composite reliability measurement. The measurement is conducted to examine if the proposed measurement for the observed variable could be trusted and reliable for future examination on different research. The measurement criteria for a variable to pass the composite reliability test is by examining the value of AVE. Should the AVE have a value of more than 0.7, the measurement of the observed variable could be trusted and considered reliable to be used in future researches [14]. According to the AVE value of each observed variable shown in Table 2, all of the AVE scores are above 0.7 that concludes the observed variable within the proposed model in this study is reliable.

\subsection{Inner Model Analysis}

The inner model evaluation is conducted to measure the robustness of the proposed conceptual model and its fitness to predict the relationship between the variables within it. The evaluation could be done by examining the coefficient of determinant $\left(\mathrm{R}^{2}\right)$ value, the predictive relevance $\left(\mathrm{Q}^{2}\right)$ value, and the Goodness of Fit. The $\mathrm{R}^{2}$ value shows how much variation of the exogen variables is generated for their endogen variables. A higher $\mathrm{R}^{2}$ shows a greater variation to describe a variation on building endogen variable by the exogen variables within the proposed conceptual model. The $\mathrm{R}^{2}$ results for this study are shown in Table 4.

Table 4. Coefficient Determinant $\left(\mathrm{R}^{2}\right)$ Value

\begin{tabular}{|c|c|c|}
\hline & R Square & $R$ Square Adjusted \\
\hline CSE & 0,242 & 0,234 \\
\hline INO & 0,435 & 0,429 \\
\hline BP & 0,489 & 0,479 \\
\hline
\end{tabular}

Following the $\mathrm{R}^{2}$ value, we could conclude that $24.2 \%$ of creative self-efficacy could be affected or influenced by adaptive resilience and planned resilience. This suggested that both resilience have a weak impact on building creative self-efficacy because $75.8 \%$ of the endogen variable is determined by other variables which are not observed on the proposed model. However, both resilience seems to moderate building innovation as they formed $43.5 \%$ of the endogen variables. Finally, resilience, creative self-efficacy, and innovation contribute to $48.9 \%$ on building business performance as an endogen variable. This suggests that exogen variables within the proposed model could moderate impact building business performance.

The $\mathrm{Q}^{2}$ is calculated using the $\mathrm{R}^{2}$ value. The $\mathrm{Q}^{2}$ determines the predictive strength of the proposed model to examine the relationship between variables. A model that has a strong predictive power to examine the relationship between the variables should have a $\mathrm{Q}^{2}$ value of more than 0.35 . Should the $\mathrm{Q}^{2}$ value fall below 0.35 , the proposed model is considered to have a moderate power to examine the relationship between the observed variables. However, if the $\mathrm{Q}^{2}$ value falls below 0.15 the proposed model is considered weak. The calculation for the $\mathrm{Q}^{2}$ for the proposed model on this study is as follow:
$\mathrm{Q}^{2}=1-\left(1-\mathrm{R}_{1}^{2}\right)\left(1-\mathrm{R}_{2}^{2}\right)$

$=1-(1-0.242)(1-0.435)(1-0.489)$

$=1-(0.758)(0.565)(0.511)$

$=0.782$

Following the $\mathrm{Q}^{2}$ calculation results, we conclude that the current proposed conceptual model has a strong predictive power to examine the relationship between the variables within it. Finally, the Goodness of Fit $(\mathrm{GoF})$ should be calculated to measure the overall fit of the model as a whole. The calculation of GoF includes the value of $\mathrm{R}^{2}$ and Average Variance Extracted (AVE) on the endogen variables within the model. The calculation for GoF on this study is as follow:

$$
\begin{aligned}
& \text { GoF }=\sqrt{A V E \times \mathrm{R}^{2}} \\
& =\sqrt{0.594 \times 0.388} \\
& =0.480
\end{aligned}
$$

[Tenenhaus et al., 2004] suggested that the value of GoF could be categorized into three categories. GoF with a value more than 0.1 but less than 0.25 should be considered weak. GoF with a value that falls between 0.25 and 0.38 should be considered medium, and GoF with a value more than 0.38 should be considered strong. Following this suggestion, we could conclude that the GoF of the current proposed model to be strong which means that the overall fit of 
the proposed model is robust to be used as hypothesis testing analysis.

\subsection{Hypotheses Testing}

Table 5. The Hypotheses Test Results

\begin{tabular}{|c|l|c|c|}
\hline Hypotheses & \multicolumn{1}{|c|}{ Relationship } & T-statistics & Mark \\
\hline H1 & Adaptive resilience $\rightarrow$ Business performance & 6,178 & Supported \\
\hline H2 & Planned Resilience $\rightarrow$ Business Performance & 1,077 & Not Supported \\
\hline H3 & Adaptive resilience $\rightarrow$ Creative self-efficacy & 1,979 & Supported \\
\hline H4 & Planned resilience $\rightarrow$ Creative self-efficacy & 3,624 & Supported \\
\hline H5 & Creative self-efficacy $\rightarrow$ Business performance & 4,813 & Supported \\
\hline H6 & Adaptive resilience $\rightarrow$ Innovation & 3,743 & Supported \\
\hline H7 & Planned resilience $\rightarrow$ Innovation & 2,768 & Supported \\
\hline H8 & Innovation $\rightarrow$ Business performance & 1,984 & Supported \\
\hline
\end{tabular}

Source: SmartPLS 3.2
Adaptive resilience has been found to have a positive and significant effect on business performance, creative self-efficacy, and innovation. These findings support previous research by [8], [28], and [11]. Following this result, we conclude that an adaptive resilience of a firm is one of its competitive advantages to sustain and develop its business performance, especially in the pandemic crisis. The competencies to adapt accordingly to threats and challenges within the business environment that was unpredicted before is a strong determinant of good business performance and is hard to challenge by competitors. We also support previous findings from [23] that adaptive resilience is best nurtured when businesses have a good leader, strong social capital, internal collaboration, organizational experience, and support from their employees.

Planned resilience is found to have a positive and significant effect on creative self-efficacy and innovation. However, we could not prove that this resilience has any influence on business performance. The result is somewhat contrary to [23] and [8], which show that resilience is a strong predictor of business performance. By examining resilience as a twodimensional observation, we could have a deeper insight into how resilience could influence business performance. Our findings suggested that a planned preparation for a predicted threat or challenge is not enough for a company to sustain its business if any unpredicted threats or challenge appears and the company did not have adaptive capabilities to resilience toward those threats and challenges.
Seven out of eight hypotheses proposed in this study are accepted. The criteria for acceptance are the $\mathrm{t}$-statistics value should be more than 1.96 (the value of t-table on 0.05 significance level). The overall results of hypotheses testing for this study are presented in Table 5.

\section{CONCLUSION}

Following the research findings on this study, we could conclude that examination of business resilience could be done in a multidimensional observation to gain a deeper insight into the relationship between resilience and business performance. We observed resilience into a twodimensional observation and found interesting results in which adaptive resilience is found to have a positive and significant effect on business performance, a contrast to planned resilience which is not. The finding suggested that to overcome threats and challenges, entrepreneurs should not only rely on their capabilities to predict threats and challenges and prepare a plan to overcome them. Good entrepreneurs should always look for ways to improve their capabilities and competencies to prepare and be ready to overcome threats and challenges that are unpredicted. A strong adaptive resilience could be determined by the leader of the business organization, its social capital, its internal collaboration, organizational experience, and support from its employees.

Theoretically, we provided a fit and robust conceptual model to examine the relationship between the variable. We have proved that a multidimensional observation for resilience is important because there is a different influence from each resilience on business performance. Practically, the findings of this study should encourage business owners and managers to start improving their 
resilience since they did not only a predictor of business sustainability but also could improve the creative self-efficacy and innovation of their business.

\subsection{Research Limitation and Future Recommendation}

The self-administered questionnaire used as data collection for this study was carefully built to reduce the bias from the respondents when giving information. However, we believe a structured interview should be the best data collection instrument for this study to gain more insight into how business owners and managers built resilience on their business. The resource limitation prohibits us to achieve those goals, thus we strongly suggest future researchers use a more precise data collection instrument to add more information that might be missing from the current study.

\section{REFERENCES}

[1] Acs, Z. J., Small business economics: A global perspective, Challenge, vol. 35, no. 6, pp. 38-44, 1992.

[2] Alves, J. C., Lok, T. C., Luo, Y., \& Hao, W., Crisis management for small business during the COVID-19 outbreak: Survival, resilience and renewal strategies of firms in Macau, 2020.

[3] Ayala, J.-C., \& Manzano, G., The resilience of the entrepreneur, Influence on the success of the business, A longitudinal analysis, Journal of Economic Psychology, vol. 42, pp. 126-135, 2014

[4] Bandura, A., Self-efficacy: Toward a unifying theory of behavioral change, Psychological Review, 1977, doi: 10.1037/0033295X.84.2.191

[5] Bernard, M.-J., \& Barbosa, S. D., Resilience and entrepreneurship: A dynamic and biographical approach to the entrepreneurial act, M@ N@ Gement, vol. 19, no. 2, pp. 89-123, 2016.

[6] De Vries, H., \& Shields, M., Towards a theory of entrepreneurial resilience: A case study analysis of New Zealand SME owner operators, New Zealand Journal of Applied Business Research, vol. 5, no. 1, pp. 33-43, 2006.

[7] Hair, J. F., Hult, G. T. M., Ringle, C. M., \& Sarstedt, M., A primer of partial least squares structural equation modelling (PLS-SEM),
SAGE Publications, 2014.

[8] Hallak, R., Assaker, G., O’Connor, P., \& Lee, C., Firm performance in the upscale restaurant sector: The effects of resilience, creative selfefficacy, innovation and industry experience, Journal of Retailing and Consumer Services, vol. 40, pp. 229-240, 2018.

[9] Haver, A., Akerjordet, K., \& Furunes, T., Wise emotion regulation and the power of resilience in experienced hospitality leaders, Scandinavian Journal of Hospitality and Tourism, vol. 14, no. 2, pp. 152-169, 2014.

[10] Hébert, R. F., \& Link, A. N., The entrepreneur as innovator, The Journal of Technology Transfer, vol. 31, no. 5, pp. 589-597, 2006.

[11] Helfat, C. E., Finkelstein, S., Mitchell, W., Peteraf, M., Singh, H., Teece, D., \& Winter, S. G., Dynamic capabilities: Understanding strategic change in organizations, John Wiley \& Sons, 2009.

[12] Home, N., Entrepreneurial orientation of grocery retailers in Finland, Journal of Retailing and Consumer Services, vol. 18, no. 4, pp. 293-301, 2011.

[13] Hussein, A. S., Penelitian bisnis dan manajemen menggunakan Partial Least Squares (PLS) dengan SmartPLS 3.0, Universitas Brawijaya, 2015.

[14] Hussein, A. S., The Importance of Knowledge Management Orientation Behaviour and Innovation on Business Performance: A Lesson From Indonesia Creative Economy Sector, AsiaPacific Management and Business Application, vol. 7, no. 2, pp. 79-90, 2018

[15] Jiang, Y., Ritchie, B. W., \& Verreynne, M., Building tourism organizational resilience to crises and disasters: A dynamic capabilities view, International Journal of Tourism Research, vol. 21, no. 6, pp. 882-900, 2019.

[16] Jung, H. S., \& Yoon, H. H., The impact of employees' positive psychological capital on job satisfaction and organizational citizenship behaviors in the hotel, International Journal of Contemporary Hospitality Management, 2015.

[17] Lee, C., Hallak, R., \& Sardeshmukh, S. R., Innovation, entrepreneurship, and restaurant perf.: A higher-order structural model, Tourism Management, vol. 53, pp. 215-228, 2016. 
[18] Madrid-Guijarro, A., Garcia, D., \& Van Auken, H., Barriers to innovation among Spanish manufacturing SMEs, Journal of Small Business Management, vol. 47, no. 4, pp. 465-488, 2009.

[19] McNaughton, R. B., \& Gray, B., Entrepreneurship and resilient communitiesintroduction to the special issue, Journal of Enterprising Communities: People and Places in the Global Economy, 2017.

[20] Miles, M. P., Lewis, G. K., Hall-Phillips, A., Morrish, S. C., Gilmore, A., \& Kasouf, C. J., The influence of entrepreneurial marketing processes and entrepreneurial self-efficacy on community vulnerability, risk, and resilience, Journal of Strategic Marketing, vol. 24, no. 1, pp. 34-46, 2016.

[21] Oke, A., Barriers to innovation management in service companies, Journal of Change Management, vol. 4, no. 1, pp. 31-44, 2004.

[22] Pérez-López, M. C., González-López, M. J., \& Rodríguez-Ariza, L., Competencies for entrepreneurship as a career option in a challenging employment environment, Career Development International, 2016.

[23] Prayag, G., Chowdhury, M., Spector, S., \& Orchiston, C., Organizational resilience and financial performance, Annals of Tourism Research, vol. 73, no. C, pp. 193-196, 2018.
[24] Renko, M., Bullough, A., \& Saeed, S., Entrepreneurship under adverse conditions: Global study of individual resilience and selfefficacy, Academy of Management Proceedings, 2016(1), 18103, 2016.

[25] Schumpeter, J. A., The general economist, In Wesley Clair Mitchell: The Economic Scientist, NBER, pp. 321-340, 1952.

[26] Singh, J., COVID - 19's Impact on the Society, Electronic Research Journal of Social Sciences and Humanities, 2(April), pp. 0-5, 2020.

[27] Tenenhaus, M., Amato, S., \& Esposito Vinzi, V., A global goodness-of-fit index for PLS, 2004.

[28] Tierney, P., \& Farmer, S. M., Creative selfefficacy: Its potential antecedents and relationship to creative performance, Academy of Management Journal, vol. 45, no. 6, pp. 11371148,2002

[29] Torres, A. P., Marshall, M. I., \& Sydnor, S., Does social capital pay off? The case of small business resilience after Hurricane Katrina, Journal of Contingencies and Crisis Management, vol. 27, no. 2, pp. 168-181, 2019.

[30] Wang, C.-J., Do ethical and sustainable practices matter? Effects of corporate citizenship on business performance in the hospitality industry, International Journal of Contemporary Hospitality Management, 2014. 